\title{
A Spherical Temperature Sensor Array Design for Near-Surface Atmospheric Temperature Studies
}

\author{
JiE YANG, QINGQUAN LiU, AND FENG Ding \\ Jiangsu Key Laboratory of Meteorological Observation and Information Processing, Nanjing University of Information \\ Science and Technology, and Jiangsu Collaborative Innovation Center on Atmospheric Environment and Equipment \\ Technology, Nanjing University of Information Science and Technology, Nanjing, China \\ RENHUI DING \\ Jiangsu Meteorological Observation Center, Nanjing, China
}

(Manuscript received 7 November 2019, in final form 30 June 2020)

\begin{abstract}
The observation accuracy of the surface air temperature less than $0.1 \mathrm{~K}$ is a requirement, stated by the meteorological and climatological community. However, the accuracy of a temperature sensor inside a shield is affected by a number of factors including solar radiation, wind speed, upwelling longwave radiation, air density, sun elevation angle, sun azimuth angle, underlying surface, precipitation, moisture, structure, and coating of the radiation shield. Due to these factors, the temperature error of the temperature sensor may be much larger than $1 \mathrm{~K}$ under adverse conditions. To improve the observation accuracy, this paper proposed a spherical temperature sensor array. A series of analytical calculations based on a computational fluid dynamics (CFD) method is performed to verify the design principle of this sensor array. The calculation results show that the temperature error ratio can be assumed as a constant. To verify the accuracy of this sensor array, simulations and observation experiments are conducted. The simulation results show that the mean difference between the temperature provided by this sensor array and the reference air temperature is $0.072 \mathrm{~K}$. The field experiment results show that a root-mean-square error (RMSE) and a mean absolute error (MAE) between the temperature provided by this sensor array and the reference air temperature are 0.173 and $0.153 \mathrm{~K}$, respectively.
\end{abstract}

\section{Introduction}

In recent years, a number of studies have been focused upon the climate change. An Intergovernmental Panel on Climate Change (IPCC) report indicated that the global averaged surface temperature increased approximately $0.6 \mathrm{~K}$ in the twentieth century. In other words, the mean increase in temperature during the twentieth century was $0.006 \mathrm{~K} \mathrm{yr}^{-1}$ (https://www.ipcc.ch/report/ar5/ $w g 3 /)$. In 2018, a special IPCC report indicated that limiting the global temperature increase to $1.5 \mathrm{~K}$ could go hand in hand with ensuring a more sustainable and equitable society. In other words, by 2100 , we should reduce the mean increase in temperature less than $0.019 \mathrm{~K} \mathrm{yr}^{-1}$ (https://www.ipcc.ch/sr15/). Fyfe et al. (2013) concluded that the global mean increase in temperature was $0.14 \pm 0.06 \mathrm{~K} \mathrm{decade}^{-1}$ by analyzing the data in the

\footnotetext{
Corresponding author: Qingquan Liu, 001980@nuist.edu.cn
}

period 1993-2012. Dillon et al. (2010) analyzed the data over the past 50 years (1961-2009), and concluded that the increases in temperature in tropical areas and in Northern Hemisphere areas were approximately 0.4 and $0.95 \mathrm{~K}$, respectively. Gleisner et al. (2015) concluded that the increase in temperature was approximately $0.8 \mathrm{~K}$ by analyzing the data over the past 30 years (1979-2013). In conclusion, the increase in surface air temperature is on the order of $0.01 \mathrm{~K} \mathrm{yr}^{-1}$.

The temperature error mainly consists of an error induced by a circuitry system, an error caused by the calibration and an error caused by the solar radiation. Because the temperature error induced by the solar radiation is significantly larger than the error caused by the calibration and the error caused by the circuit system, it has been researched by a number of papers (Lopardo et al. 2014; Lin et al. 2001a; Holden et al. 2013). Harrison and Wood concluded that the radiation shield or the screen will reduce the airflow rate near the temperature 
sensor, which will uncouple the sensor from the air whose temperature it is meant to measure (Harrison and Wood 2012; Harrison 2011). In recent years, a number of studies have been focused upon the performance improvement of the radiation shields and screens (Anderson and Baumgartner 1998; Hubbard et al. 2001; van der Meulen and Brandsma 2008; Xiong et al. 2017; de Jong et al. 2015). The observation accuracy of these instruments is remarkable impacted by a number of factors, particularly wind (Lin et al. 2001a), radiation (Lin et al. 2001b), coating (Lopardo et al. 2014) and underlying surface (Lin et al. 2005). In addition, a variety of shields with different structures have been proposed. Erell et al. (2005) designed and evaluated a number of shields through the experimental method. The experimental results indicated that the temperature errors of these shields were up to $0.8 \mathrm{~K}$ with the air temperature reference from a Stevenson screen. Hubbart (2011) evaluated a shield under cloudless conditions. The experimental results indicated that the average temperature error caused by the solar radiation was $2.84 \mathrm{~K}$ with the air temperature reference from a Gill aspirated temperature sensor.

The flowing air is beneficial to reduce the temperature error by facilitating the diffusion of radiant heat. Hence, the aspirated radiation shield has been used widely in the weather station due to this technical advantaged afforded. A number of studies have been focused upon the performance of the aspirated radiation shields (Georges and Kaser 2002; Mahajan et al. 2005; Thomas and Smoot 2013). R. M. Young Company designed a 43502 aspirated radiation shield with a high forced airflow rate $\left(5-11 \mathrm{~m} \mathrm{~s}^{-1}\right)$. The product manual of this shield indicated that the temperature error is $0.2 \mathrm{~K}$, when the solar radiation intensity is $1000 \mathrm{~W} \mathrm{~m}^{-2}$, and the airflow rate is $11 \mathrm{~m} \mathrm{~s}^{-1}$. Met One Company designed a 076B aspirated radiation shield with approximately $5 \mathrm{~m} \mathrm{~s}^{-1}$ forced airflow rate. Thomas and Smoot (2013) designed and evaluated an aspirated shield. The temperature error of this aspirated shield is approximately $0.2 \mathrm{~K}$. Further analysis indicated that the lower temperature error may be obtained by increasing force airflow rate. However, a high-power air pump is required to supply a higher force airflow rate. Hence, the applications of these aspirated radiation shields may be limited by the high-power requirement and reliability.

This paper presents a spherical temperature sensor array to improve the observation accuracy. To reduce the error induced by the circuitry system, a potentiometer bridge circuitry system is designed. To reduce the error caused by the calibration, a $1595 \mathrm{~A}$ superthermometer from Fluke and several fixed points of International Temperature Scale of 1990 (ITS-90) from Isotech are applied to calibrate the sensors directly. The combined error of the calibration error and the circuit system error may be reduced to the order of $0.01 \mathrm{~K}$. However, even if the error of the sensor is smaller than $0.01 \mathrm{~K}$, there are many other factors that may lead to a measurement uncertainty. It is difficult to analyze all the factors during the design process. Because the temperature error induced by the solar radiation is much larger than the temperature error induced by some other factors including the longwave radiation during nighttime, we start this research by focusing on the relatively large temperature error caused by the solar radiation during daytime. To verify the design principle of this sensor array, a series of analytical calculations based on a computational fluid dynamics (CFD) method is performed. To verify the accuracy of this sensor array, simulations and observation experiments are conducted.

\section{Design of the spherical temperature sensor array}

\section{a. Design principle}

When three spherical temperature sensors A, B, and $\mathrm{C}$ with different coatings are placed in the same environment, the temperature error ratio $\eta$ between two of them is closely related to the coating absorptivity. In addition, the temperature error ratio $\eta$ depends on the mixture of visible and infrared radiation.

Environmental condition 1:

$$
\begin{aligned}
& \frac{\Delta T_{\mathrm{B}}}{\Delta T_{\mathrm{A}}}=\frac{T_{\mathrm{mea}(\mathrm{B})}-T_{\mathrm{ref}(1)}}{T_{\text {mea(A) }}-T_{\text {ref( }(1)}}=\eta_{(\mathrm{AB}) 1}, \\
& \frac{\Delta T_{\mathrm{C}}}{\Delta T_{\mathrm{A}}}=\frac{T_{\text {mea(C) }}-T_{\text {ref }(1)}}{T_{\text {mea(A) }}-T_{\operatorname{ref}(1)}}=\eta_{(\mathrm{AC}) 1}, \\
& \frac{\Delta T_{\mathrm{C}}}{\Delta T_{\mathrm{B}}}=\frac{T_{\text {mea(C) }}-T_{\text {ref(1) }}}{T_{\text {mea(B) }}-T_{\text {ref }(1)}}=\eta_{(\mathrm{BC}) 1} .
\end{aligned}
$$

Environmental condition 2:

$$
\begin{gathered}
\frac{\Delta T_{\mathrm{B}}}{\Delta T_{\mathrm{A}}}=\frac{T_{\mathrm{mea}(\mathrm{B})}-T_{\mathrm{ref}(2)}}{T_{\mathrm{mea}(\mathrm{A})}-T_{\mathrm{ref}(2)}}=\eta_{(\mathrm{AB}) 2}, \\
\frac{\Delta T_{\mathrm{C}}}{\Delta T_{\mathrm{A}}}=\frac{T_{\mathrm{mea}(\mathrm{C})}-T_{\mathrm{ref}(2)}}{T_{\mathrm{mea}(\mathrm{A})}-T_{\mathrm{ref}(2)}}=\eta_{(\mathrm{AC}) 2}, \\
\frac{\Delta T_{\mathrm{C}}}{\Delta T_{\mathrm{B}}}=\frac{T_{\mathrm{mea}(\mathrm{C})}-T_{\mathrm{ref}(2)}}{T_{\mathrm{mea}(\mathrm{B})}-T_{\mathrm{ref}(2)}}=\eta_{(\mathrm{BC}) 2},
\end{gathered}
$$

where $\Delta T_{\mathrm{A}}, \Delta T_{\mathrm{B}}$, and $\Delta T_{\mathrm{C}}$ are the temperature errors of the sensors A, B, and C, respectively; $T_{\text {mea(A) }}, T_{\text {mea(B) }}$, and $T_{\mathrm{mea}(\mathrm{C})}$ are the temperature observed values provided 
by the sensors $A, B$, and $C$, respectively; $T_{\operatorname{ref}(1)}$ and $T_{\operatorname{ref}(2)}$ are the reference air temperatures of the environmental conditions 1 and 2 , respectively; $\eta_{(\mathrm{AB}) 1}$ and $\eta_{(\mathrm{AB}) 2}$ are temperature error ratios of the two sensors $\mathrm{A}$ and $\mathrm{B}$ under environmental conditions 1 and 2, respectively; $\eta_{\text {(AC)1 }}$ and $\eta_{\text {(AC)2 }}$ are temperature error ratios of the two sensors $\mathrm{A}$ and $\mathrm{C}$; and $\eta_{(\mathrm{BC}) 1}$ and $\eta_{(\mathrm{BC}) 2}$ are temperature error ratios of the two sensors $\mathrm{B}$ and $\mathrm{C}$.

The temperature error ratio $\eta$ may fluctuate slightly with different wavelengths of visible and infrared radiation. The change of ambient temperature will also cause a slight difference in $\eta$. Therefore, to quantify the relationship among $\eta$, visible and infrared radiation, and ambient temperature accurately, a high-accuracy instrument matrix may be needed to observe the radiation of each wave band. Hence, it is difficult to quantify the radiation error ratio $\eta$ accurately at present. However, the temperature dependence of $\eta$ is weak, and the average values of $\eta$ reduce the error considerably. Therefore, we assume this radiation error ratio $\eta$ as a constant. In other words, even if the environmental variables (wind speed, solar radiation intensity, infrared radiation intensity, diffuse solar radiation intensity, air density, ambient temperature, etc.) change, the temperature error ratios remain the same $\left[\eta_{(\mathrm{AB}) 1}=\eta_{(\mathrm{AB}) 2}, \eta_{(\mathrm{AC}) 1}=\eta_{(\mathrm{AC}) 2}\right.$, $\left.\eta_{(\mathrm{BC}) 1}=\eta_{(\mathrm{BC}) 2}\right]$, as long as these spherical sensors have the same diameter and surface area. Therefore, if $\eta$ is known, the actual air temperature may be obtained by using Eq. (7):

$$
\begin{aligned}
T_{\mathrm{act}} & =\frac{\eta_{(\mathrm{AB})} T_{\mathrm{mea}(\mathrm{A})}-T_{\mathrm{mea}(\mathrm{B})}}{\eta_{(\mathrm{AB})}^{-1}}=\frac{\eta_{(\mathrm{AC})} T_{\mathrm{mea}(\mathrm{A})}-T_{\mathrm{mea}(\mathrm{C})}}{\eta_{(\mathrm{AC})}^{-1}} \\
& =\frac{\eta_{(\mathrm{BC})} T_{\mathrm{mea}(\mathrm{B})}-T_{\mathrm{mea}(\mathrm{C})}}{\eta_{(\mathrm{BC})}^{-1}}
\end{aligned}
$$

where $T_{\text {mea(A) }}, T_{\text {mea(B) }}$, and $T_{\text {mea(C) }}$ are the air temperature observed values provided by the sensors $\mathrm{A}, \mathrm{B}$, and C, respectively.

\section{b. Simulation model construction}

The spherical temperature sensor array contains three sensors A, B, and C. Three copper spherical shells with different coatings are manufactured for these sensors. A platinum resistance probe is fixed at the center position of the copper spherical shell by using a heatconducted silica gel. Because moisture can shortcircuit the platinum resistance probe, a sealant is adopted to prevent the moisture going into the inside of the copper spherical shell. The diameter and thickness of the copper spherical shell are 8 and $0.5 \mathrm{~mm}$, respectively (Fig. 1).

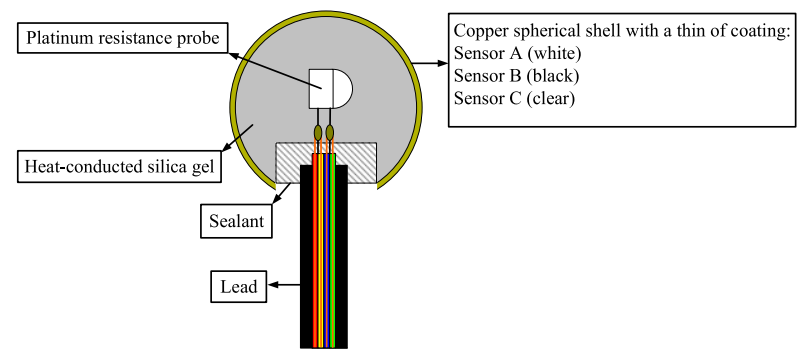

FIG. 1. Internal structure schematics of the spherical temperature sensor. The sensors A and B are covered with a thin layer of white coating and a thin layer of black coating, respectively. There is no coating on the surface of the sensor C.

The unstructured mesh technology from a CFD software ICEM is adopted to generate a tetrahedral mesh of the spherical temperature sensor array (Huang et al. 2017; Davis 2015). To model the heat exchange between the sensor array and air accurately, a boundary layer grid is introduced in the mesh model. To obtain the temperature results accurately, a CFD software Fluent is used for numerical calculation (Kumar et al. 2017; Baghapour and Sullivan 2017; Qian et al. 2018). A standard semi-implicit method for pressure linked equations (SIMPLE) algorithm, a standard initialization method, a $k-\varepsilon$ model and a solar ray tracing model are used in the CFD model (Stafford et al. 2012). In addition, to assure the validity of the CFD results, boundary conditions are set according to the physical environment. The materials properties of the sensor array are listed in Table 1.

\section{c. Numerical calculation}

To quantify the temperature error ratios $\left[\eta_{(\mathrm{AB})}, \eta_{(\mathrm{AC})}\right.$ and $\left.\eta_{(\mathrm{BC})}\right]$ of this sensor array, the CFD model of the sensor array is calculated. The solar radiation intensity, diffuse solar radiation intensity, wind speed, altitude of weather station, absorptivity of coating of the sensor A, absorptivity of the sensor $\mathrm{B}$ and absorptivity of the sensor $\mathrm{C}$ are $1000 \mathrm{~W} \mathrm{~m}^{-2}, 200 \mathrm{~W} \mathrm{~m}^{-2}, 1 \mathrm{~m} \mathrm{~s}^{-1}, 0 \mathrm{~km}, 0.1,0.5$, and 0.9, respectively. The temperature field is shown in Fig. 2 .

As is shown in the temperature field of Fig. 2, the temperature errors of sensors $\mathrm{A}, \mathrm{B}$, and $\mathrm{C}$ are approximately

TABLE 1. Material properties of the spherical temperature sensor array used in the CFD model.

\begin{tabular}{lcc}
\hline \hline \multicolumn{1}{c}{ Material } & $\begin{array}{c}\text { Heat capacity } \\
\left(\mathrm{J} \mathrm{kg}^{-1} \mathrm{~K}^{-1}\right)\end{array}$ & $\begin{array}{c}\text { Thermal } \\
\text { conductivity }\left(\mathrm{W} \mathrm{m}^{-1} \mathrm{~K}^{-1}\right)\end{array}$ \\
Copper & 381 & 387.6 \\
Heat-conducted & 1700 & 2.9 \\
$\quad$ silica gel & & \\
Sealant & 2100 & 0.9 \\
Plastic & 1591 & 0.2 \\
\hline
\end{tabular}




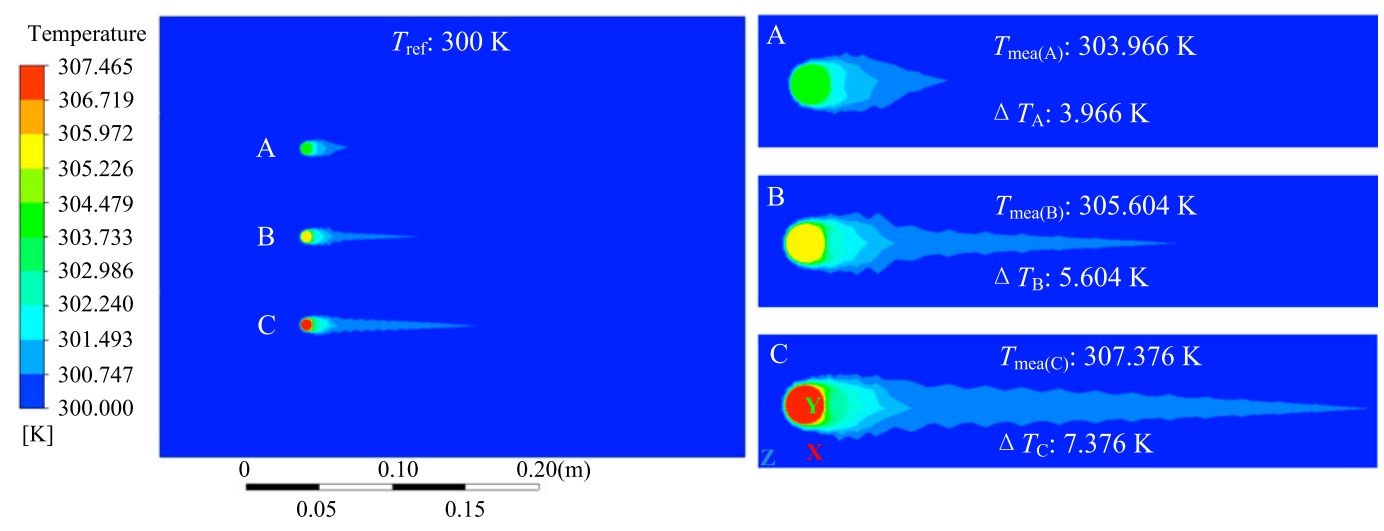

FIG. 2. Temperature field simulation result of the spherical temperature sensor array. A solar radiation intensity of $1000 \mathrm{~W} \mathrm{~m}^{-2}$, diffuse solar radiation intensity of $200 \mathrm{~W} \mathrm{~m}^{-2}$, wind speed of $1 \mathrm{~m} \mathrm{~s}^{-1}$, air density of $1.225 \mathrm{~kg} \mathrm{~m}^{-3}$, absorptivity of coating of the sensor A of 0.1 , absorptivity of the sensor B of 0.5 , and absorptivity of the sensor C of 0.9 are applied as environmental conditions.

3.966, 5.604, and $7.376 \mathrm{~K}$, respectively. Hence, the temperature error ratios $\eta_{(\mathrm{AB})}, \eta_{(\mathrm{AC})}$, and $\eta_{(\mathrm{BC})}$ are 1.413 , 1.860 , and 1.315 , respectively.

\section{d. Analysis of temperature error ratios}

To verify that the ambient temperature dependence of the $\eta$ is weak, several simulations are implemented under different environment temperatures $(273,283$, $293,300,310$, and $320 \mathrm{~K})$. The temperature error ratios are listed in Table 2.

As is shown in Table 2, these temperature error ratios vary slightly. In addition, the temperature error ratio may fluctuate slightly with different wavelengths of visible and infrared. We assume this radiation error ratio $\eta$ as a constant. To prove this feature, the CFD model is numerically calculated under different environmental conditions. The wind speed, solar radiation intensity, diffuse solar radiation intensity and altitude are ranging from $0.5-8 \mathrm{~m} \mathrm{~s}^{-1}, 100-1000 \mathrm{~W} \mathrm{~m}^{-2}, 20-200 \mathrm{~W} \mathrm{~m}^{-2}$, and $0-5 \mathrm{~km}$, respectively. The default values of the solar radiation intensity, diffuse solar radiation intensity, wind speed, and altitude are $1000 \mathrm{~W} \mathrm{~m}^{-2}, 200 \mathrm{~W} \mathrm{~m}^{-2}, 1 \mathrm{~m} \mathrm{~s}^{-1}$, and $0 \mathrm{~km}$, respectively. The temperature errors calculated by the CFD method under different environmental conditions are shown in Fig. 3.

As is shown in Fig. 4, 18 sensors with different coatings are labeled from A to R. The temperature errors of these 18 sensors under different conditions are extracted by classifying the results shown in Fig. 3 . Any two sensors of these sensors can form an absorptivity combination. A total of 306 absorptivity combinations can be formed as follows: $\mathrm{AB}, \mathrm{AC}, \mathrm{AD}$, etc. Sixteen absorptivity combinations of them are chosen for analysis. The 16 absorptivity combinations are shown in Fig. 4.
The temperature error ratios of these 16 combinations can be obtained by analyzing the 18 sets of temperature error results. The temperature error ratios for these 16 combinations under the 24 sets of environmental conditions are shown in Fig. 5.

As is shown in Fig. 5, the temperature error ratio curves remained basically level. For example, the average temperature error ratio $\overline{\eta_{(\mathrm{AQ})}}$, the standard deviation of the temperature error ratio $\eta_{(\mathrm{AQ})}$, the total number of sampling $n$, the upper of $95 \%$ confidence interval, and the lower of $95 \%$ confidence interval are $1.852,0.0028,24,1.857$, and 1.847 , respectively. Therefore, the change of the temperature error ratio may be negligible. In conclusion, the temperature error ratio may be assumed as a fixed constant under different environmental conditions. Therefore, if the value of the temperature error ratio is obtained accurately, the actual air temperature may be obtained by using Eq. (7).

\section{Experiment}

To verify the actual performance of the spherical temperature sensor array, several simulations, laboratory

TABLE 2. Simulation results of the temperature error ratios $\left[\eta_{(\mathrm{AB})}, \eta_{(\mathrm{AC})}\right.$, and $\left.\eta_{(\mathrm{BC})}\right]$ are obtained under the conditions of different temperatures $(273,283,293,300,310$, and $320 \mathrm{~K})$, solar radiation intensity $\left(1000 \mathrm{~W} \mathrm{~m}^{-2}\right)$, diffuse solar radiation intensity $\left(200 \mathrm{~W} \mathrm{~m}^{-2}\right)$, wind speed $\left(1 \mathrm{~m} \mathrm{~s}^{-1}\right)$, altitude of weather station $(0 \mathrm{~km})$, absorptivity of coating of the sensor A (0.1), absorptivity of the sensor $\mathrm{B}(0.5)$, and absorptivity of the sensor $\mathrm{C}(0.9)$.

\begin{tabular}{lcccccc}
\hline \hline & \multicolumn{7}{c}{ Temperature (K) } \\
\cline { 2 - 7 } & 273 & 283 & 293 & 300 & 310 & 320 \\
\hline$\eta_{(\mathrm{AB})}$ & 1.395 & 1.403 & 1.409 & 1.413 & 1.411 & 1.397 \\
$\eta_{(\mathrm{AC})}$ & 1.871 & 1.865 & 1.852 & 1.860 & 1.857 & 1.845 \\
$\eta_{\text {(BC) }}$ & 1.312 & 1.325 & 1.343 & 1.316 & 1.319 & 1.337 \\
\hline
\end{tabular}



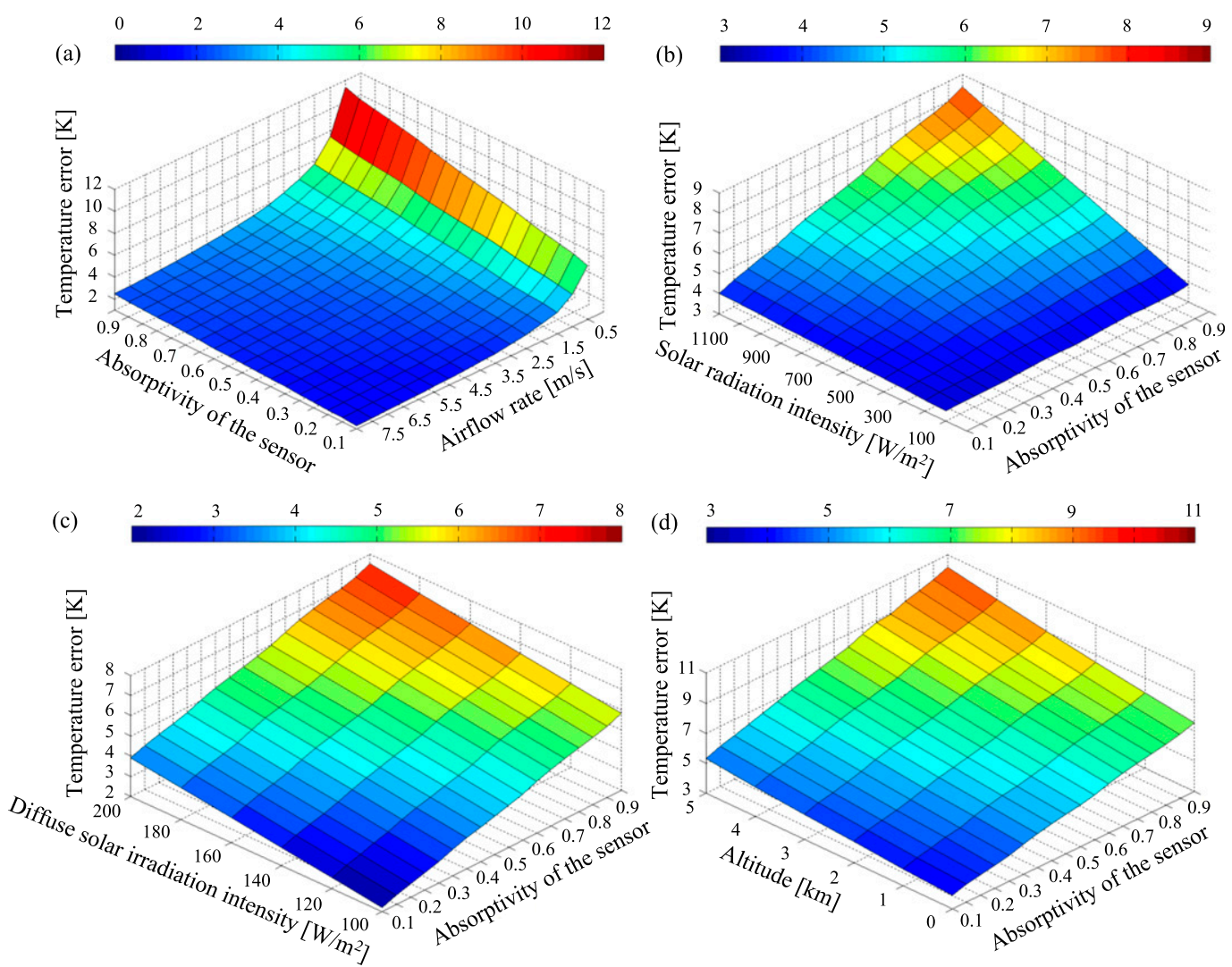

FIG. 3. Temperature error simulation results of the spherical temperature sensor under different conditions: (a) wind speed $\left(0.5-8 \mathrm{~m} \mathrm{~s}^{-1}\right)$, (b) solar radiation intensity $\left(100-1000 \mathrm{~W} \mathrm{~m}^{-2}\right)$, (c) diffuse solar radiation intensity (20$\left.200 \mathrm{~W} \mathrm{~m}^{-2}\right)$, and (d) altitude of weather station $(0-5 \mathrm{~km})$. The default values of the solar radiation intensity, diffuse solar radiation intensity, wind speed, and altitude are $1000 \mathrm{~W} \mathrm{~m}^{-2}, 200 \mathrm{~W} \mathrm{~m}^{-2}, 1 \mathrm{~m} \mathrm{~s}^{-1}$, and $0 \mathrm{~km}$, respectively.

experiments and field experiments are implemented. The spherical temperature sensors A and B are covered with a thin of layer white coating and a thin of layer black coating, respectively. There is no coating on the surface of the spherical temperature sensor $\mathrm{C}$.

\section{a. Simulations}

The reference air temperature is $300 \mathrm{~K}$ during the simulations. The absorptivities of the coatings of the sensors A, B, and C are 0.1, 0.5, and 0.9, respectively. The values of the airflow rate, solar radiation intensity, diffuse solar radiation intensity and altitude during the simulations are listed in Table 3.

First, the temperature errors $\left(\Delta T_{\mathrm{A}}, \Delta T_{\mathrm{B}}\right.$, and $\left.\Delta T_{\mathrm{C}}\right)$ of the sensors $\mathrm{A}, \mathrm{B}$, and $\mathrm{C}$ under different conditions are provided by the CFD method. Then, the temperature error ratios $\left[\eta_{(\mathrm{AB})}, \eta_{(\mathrm{AC})}\right.$, and $\left.\eta_{(\mathrm{BC})}\right]$ can be obtained by using Eqs. (1), (2), and (3), respectively. Second, the

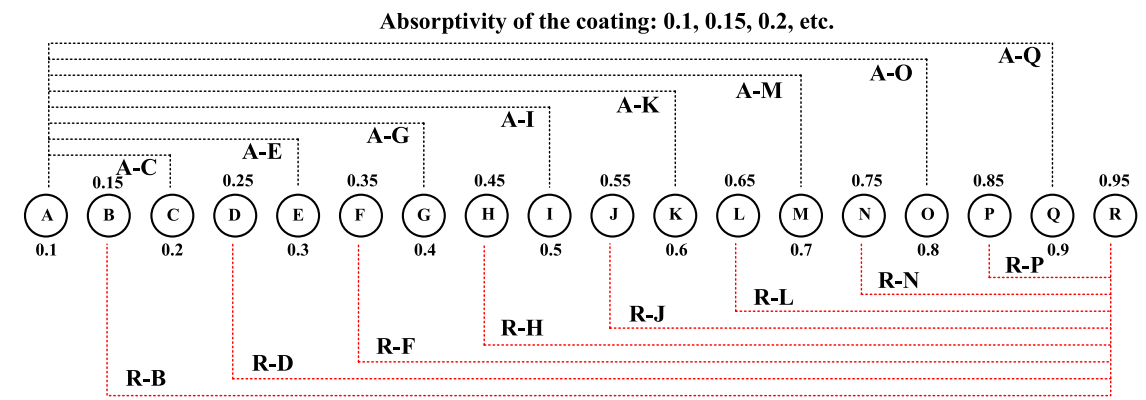

FIG. 4. Eighteen sensors with different coatings are labeled from A to R. Sixteen absorptivity combinations are chosen for analysis. 

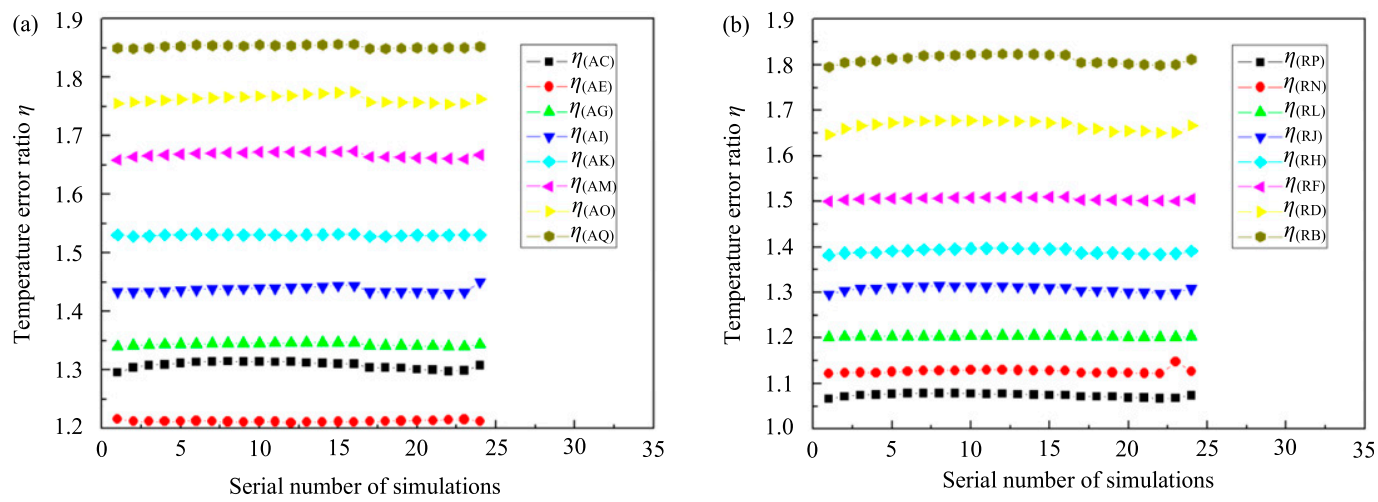

FIG. 5. Temperature error ratios for 16 absorptivity combinations under 24 sets of environmental conditions.

mean temperature error ratios $\left[\overline{\eta_{(\mathrm{AB})}}, \overline{\eta_{(\mathrm{AC})}}\right.$, and $\left.\overline{\eta_{(\mathrm{BC})}}\right]$ can be obtained. Finally, the air temperatures $\left[T_{(\mathrm{AB})}\right.$, $T_{(\mathrm{AC})}$, and $\left.T_{(\mathrm{BC})}\right]$ can be obtained by using Eq. (7) with the help of mean temperature error ratios. The air temperatures $T_{(\mathrm{ABC})}$ is the average of $\left[T_{(\mathrm{AB})}, T_{(\mathrm{AC})}\right.$, and $\left.T_{(\mathrm{BC})}\right]$.

The temperature errors $\left[\Delta T_{(\mathrm{A})}, \Delta T_{(\mathrm{B})}, \Delta T_{(\mathrm{C})}\right]$ of the sensors $(\mathrm{A}, \mathrm{B}, \mathrm{C})$, the temperature error ratios $\left[\eta_{(\mathrm{AB})}\right.$, $\left.\eta_{(\mathrm{AC})}, \eta_{(\mathrm{BC})}\right]$, the air temperatures $\left[T_{(\mathrm{AB})}, T_{(\mathrm{AC})}, T_{(\mathrm{BC})}\right.$, $\left.T_{(\mathrm{ABC})}\right]$ and the reference air temperature $T_{\text {ref }}$ are listed in Table 4.

The means of the temperature error ratios $\left[\eta_{(\mathrm{AB})}\right.$, $\eta_{(\mathrm{AC})}$, and $\left.\eta_{(\mathrm{BC})}\right]$ are $1.394,1.816$, and 1.302 , respectively. The standard deviations of these temperature error ratios $\eta_{(\mathrm{AB})}, \eta_{(\mathrm{AC})}$, and $\eta_{(\mathrm{BC})}$ are $0.016,0.042$, and 0.016, respectively. Comparisons between the reference air temperature of $300 \mathrm{~K}$ and the calculated temperature results have been performed to verify the efficiency of the sensor array. The average difference between the air temperature given by the sensor array and the reference air temperature is $0.072 \mathrm{~K}$.

\section{b. Observation experiments}

To further verify the observation accuracy of the spherical temperature sensor array, laboratory and field observation experiments are implemented. A temperature error observation platform based on a solar simulator, a low-pressure wind tunnel, and a CMP21 Pyranometer is adopted to perform the laboratory experiments. Because the sensor $C$ always protected from the sun rays, it serves as a temperature reference during the laboratory experiments. The platform is shown in Fig. 6a. Field experiments are performed in the field at Nanjing University of Information Science and Technology Site $\left(32.12^{\circ} \mathrm{N}, 118.42^{\circ} \mathrm{E}\right.$, elevation $\left.22 \mathrm{~m}\right)$ on clear days. The sensor array and a temperature sensor equipped with a 076B aspirated radiation shield are mounted onto a frame at a height of $1.5 \mathrm{~m}$ over grass.

TABLE 3. Values of the airflow rate, solar radiation intensity, diffuse solar radiation intensity, and altitude of weather station in the 12 sets of simulations. When the altitudes of weather station are $0,1,2,3,4$, and $5 \mathrm{~km}$, the air densities are $1.225,1.1116,1.0065,0.90912$, 0.81983 , and $0.73612 \mathrm{~kg} \mathrm{~m}^{-3}$, respectively.

\begin{tabular}{|c|c|c|c|c|}
\hline $\begin{array}{l}\text { Serial number of } \\
\text { simulations }\end{array}$ & $\begin{array}{c}\text { Airflow } \\
\text { rate }\left(\mathrm{m} \mathrm{s}^{-1}\right)\end{array}$ & $\begin{array}{c}\text { Solar radiation } \\
\text { intensity }\left(\mathrm{W} \mathrm{m}^{-2}\right)\end{array}$ & $\begin{array}{l}\text { Diffuse solar radiation } \\
\text { intensity }\left(\mathrm{W} \mathrm{m}^{-2}\right)\end{array}$ & $\begin{array}{l}\text { Altitude } \\
(\mathrm{km})\end{array}$ \\
\hline 1 & 0.3 & 780 & 178 & 0 \\
\hline 2 & 0.4 & 800 & 180 & 1 \\
\hline 3 & 0.5 & 820 & 182 & 2 \\
\hline 4 & 0.6 & 850 & 185 & 3 \\
\hline 5 & 0.7 & 880 & 188 & 4 \\
\hline 6 & 0.8 & 900 & 190 & 5 \\
\hline 7 & 0.9 & 920 & 192 & 0 \\
\hline 8 & 1.0 & 950 & 195 & 1 \\
\hline 9 & 1.2 & 980 & 198 & 2 \\
\hline 10 & 1.5 & 1000 & 200 & 3 \\
\hline 11 & 2.0 & 990 & 196 & 0 \\
\hline 12 & 3.0 & 960 & 197 & 0 \\
\hline
\end{tabular}


TABLE 4. The temperature errors $\left(\Delta T_{\mathrm{A}}, \Delta T_{\mathrm{B}}\right.$, and $\left.\Delta T_{\mathrm{C}}\right)$ are obtained under the 12 sets of simulation conditions listed in Table 3 . The temperature error ratios $\left[\eta_{(\mathrm{AB})}, \eta_{(\mathrm{AC})}\right.$, and $\left.\eta_{(\mathrm{BC})}\right]$ are calculated by using these temperature errors. The air temperatures $\left[T_{(\mathrm{AB})}, T_{(\mathrm{AC})}\right.$, and $\left.T_{(\mathrm{BC})}\right]$ are given by Eq. (7) by using the average of temperature error ratios $\left[\overline{\eta_{(\mathrm{AB})}}=1.394, \overline{\eta_{(\mathrm{AC})}}=1.816, \overline{\eta_{(\mathrm{BC})}}=1.302\right]$. The air temperature $T_{(\mathrm{ABC})}$ is the mean of $\left[T_{(\mathrm{AB})}, T_{(\mathrm{AC})}\right.$, and $\left.T_{(\mathrm{BC})}\right] . T_{\text {ref }}$ is the reference temperature $(300 \mathrm{~K})$.

\begin{tabular}{|c|c|c|c|c|c|c|c|c|c|c|c|}
\hline \multirow{2}{*}{$\begin{array}{l}\text { Serial number } \\
\text { of simulations }\end{array}$} & \multicolumn{3}{|c|}{$\begin{array}{c}\text { Temperature } \\
\text { error }(\mathrm{K})\end{array}$} & \multicolumn{3}{|c|}{$\begin{array}{c}\text { Temperature } \\
\text { error ratio }\end{array}$} & \multirow[b]{2}{*}{$T_{(\mathrm{AB})}(\mathrm{K})$} & \multirow[b]{2}{*}{$T_{(\mathrm{AC})}(\mathrm{K})$} & \multirow[b]{2}{*}{$T_{(\mathrm{BC})}(\mathrm{K})$} & \multirow[b]{2}{*}{$T_{(\mathrm{ABC})}(\mathrm{K})$} & \multirow[b]{2}{*}{$T_{\text {ref }}(\mathrm{K})$} \\
\hline & $\Delta T_{\mathrm{A}}$ & $\Delta T_{\mathrm{B}}$ & $\Delta T_{\mathrm{C}}$ & $\eta_{(\mathrm{AB})}$ & $\eta_{(\mathrm{AC})}$ & $\eta_{(\mathrm{BC})}$ & & & & & \\
\hline 1 & 6.965 & 9.528 & 12.185 & 1.368 & 1.749 & 1.279 & 300.460 & 300.568 & 300.730 & 300.586 & 300 \\
\hline 2 & 6.368 & 8.740 & 11.208 & 1.372 & 1.760 & 1.282 & 300.348 & 300.437 & 300.568 & 300.451 & 300 \\
\hline 3 & 6.024 & 8.292 & 10.665 & 1.376 & 1.770 & 1.286 & 300.268 & 300.337 & 300.434 & 300.346 & 300 \\
\hline 4 & 5.859 & 8.133 & 10.474 & 1.388 & 1.788 & 1.288 & 300.087 & 300.203 & 300.381 & 300.224 & 300 \\
\hline 5 & 5.797 & 8.067 & 10.445 & 1.392 & 1.802 & 1.295 & 300.036 & 300.101 & 300.193 & 300.110 & 300 \\
\hline 6 & 5.781 & 8.061 & 10.465 & 1.394 & 1.810 & 1.298 & 299.994 & 300.041 & 300.101 & 300.045 & 300 \\
\hline 7 & 4.038 & 5.642 & 7.380 & 1.397 & 1.828 & 1.308 & 299.967 & 299.942 & 299.887 & 299.932 & 300 \\
\hline 8 & 4.088 & 5.741 & 7.524 & 1.404 & 1.841 & 1.311 & 299.893 & 299.877 & 299.837 & 299.869 & 300 \\
\hline 9 & 3.956 & 5.573 & 7.330 & 1.409 & 1.853 & 1.315 & 299.852 & 299.821 & 299.755 & 299.809 & 300 \\
\hline 10 & 3.714 & 5.250 & 6.914 & 1.414 & 1.862 & 1.317 & 299.816 & 299.792 & 299.740 & 299.783 & 300 \\
\hline 11 & 2.558 & 3.618 & 4.790 & 1.414 & 1.873 & 1.324 & 299.868 & 299.823 & 299.737 & 299.809 & 300 \\
\hline 12 & 2.022 & 2.835 & 3.745 & 1.402 & 1.852 & 1.321 & 299.959 & 299.911 & 299.822 & 299.897 & 300 \\
\hline
\end{tabular}

Three spherical temperature sensors are installed in the form of an equilateral triangle with a long side. The temperature sensor inside the $076 \mathrm{~B}$ aspirated radiation shield served as a temperature reference. The platform is shown in Fig. 6b.

One hundred laboratory observed results and two days of field observed results have been used to obtain the temperature error ratios $\eta_{(\mathrm{AB})}, \eta_{(\mathrm{AC})}$, and $\eta_{(\mathrm{BC})}$. These observed temperature data of the sensors A, B, and $\mathrm{C}$ are shown in Figs. $7 \mathrm{a}$ and $7 \mathrm{c}$. The temperature error ratios $\left[\eta_{(\mathrm{AB})}, \eta_{(\mathrm{AC})}\right.$, and $\left.\eta_{(\mathrm{BC})}\right]$ can be obtained by using the temperature observed results shown in Figs. 7a and 7c with the help of Eqs. (1), (2), and (3). The temperature error ratios $\left[\eta_{(\mathrm{AB})}, \eta_{(\mathrm{AC})}\right.$, and $\left.\eta_{(\mathrm{BC})}\right]$, the mean (a)

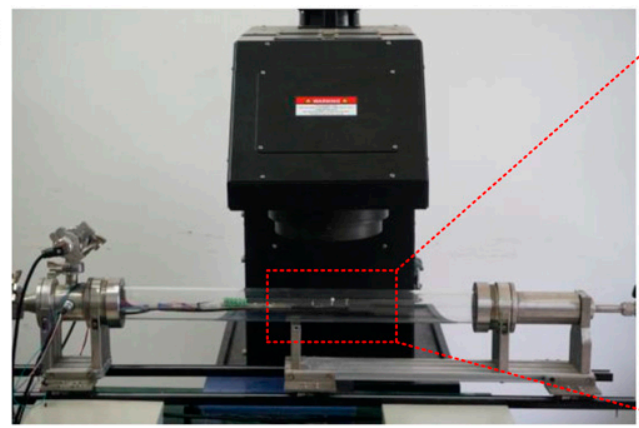

(b)

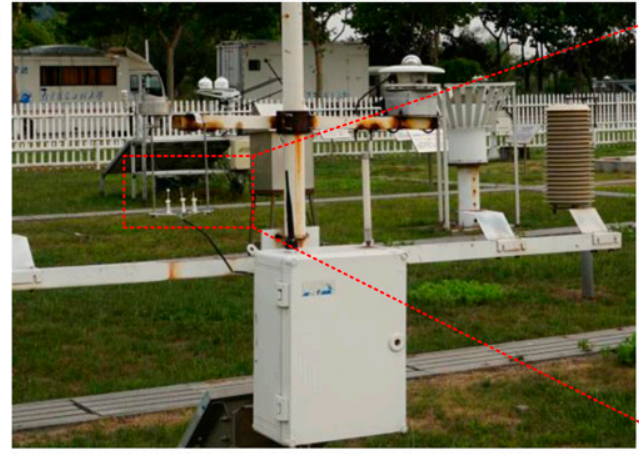

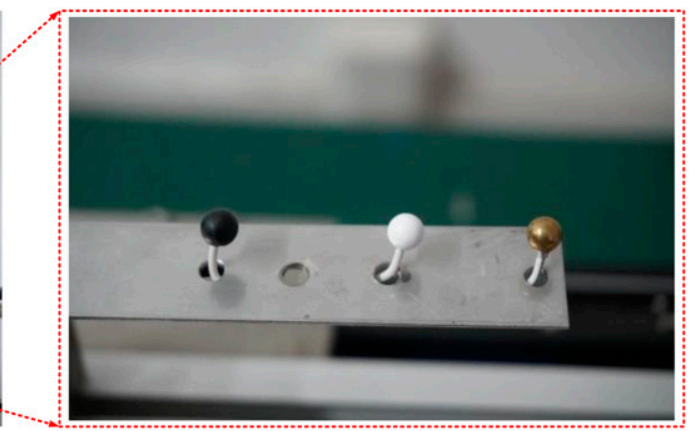

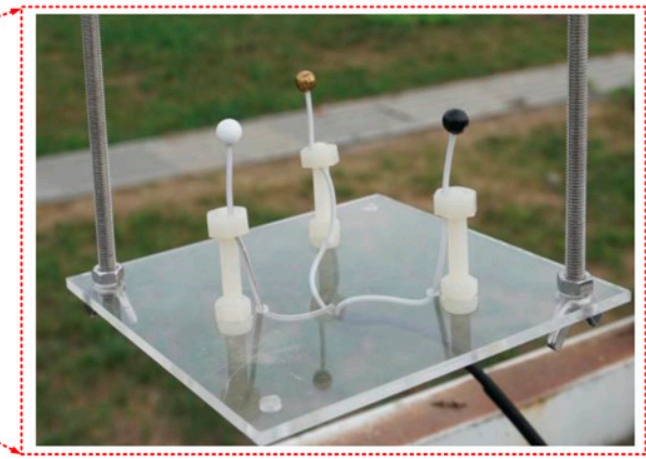

FIG. 6. Photos of experiment setup: (a) a temperature error observation platform based on a solar simulator and a low-pressure wind tunnel in the laboratory and (b) a temperature error observation platform in the filed. 

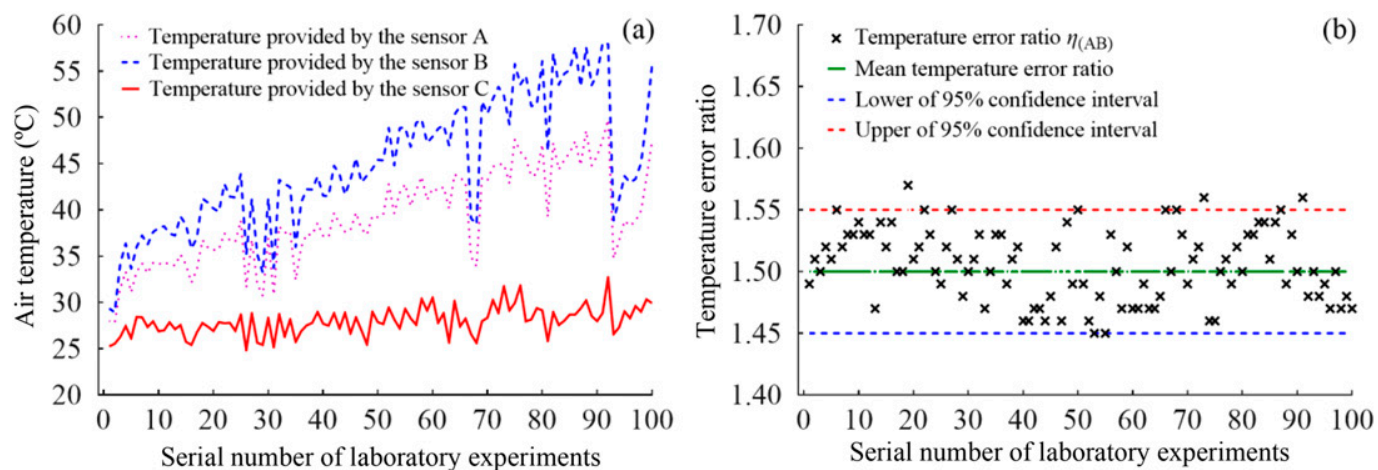

(b)
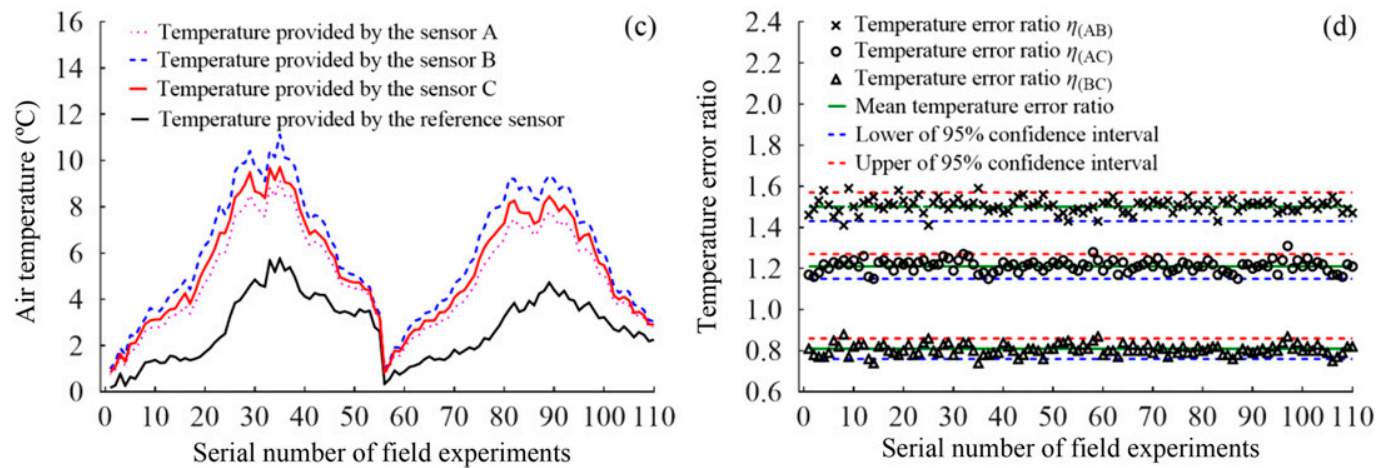

FIG. 7. Air temperature observed results and the corresponding temperature error ratios. (a) The air temperature observed results of the sensor A (dotted line), B (dashed line), and C (solid line) in the laboratory, where the sensor C installed in shadow served as a reference. (b) The corresponding temperature error ratios provided by these temperature results in the laboratory. (c) The temperature observed results of the sensors A, B, and C as well as reference sensor in the field. (d) The corresponding temperature error ratios provided by these temperature results in the field.

temperature error ratios $\left[\overline{\eta_{(\mathrm{AB})}}, \overline{\eta_{(\mathrm{AC})}}\right.$, and $\left.\overline{\eta_{(\mathrm{BC})}}\right]$, the upper and lower of $95 \%$ confidence intervals are shown in Figs. $7 \mathrm{~b}$ and $7 \mathrm{~d}$.

As is shown in Fig. $7 b$, the average temperature error ratio $\overline{\eta_{(\mathrm{AB})}}$, the standard deviation of $\eta_{(\mathrm{AB})}$, the total number of sampling $n$, the upper $95 \%$ confidence interval, and the lower $95 \%$ confidence interval are 1.5 , $0.029,100,1.55$, and 1.45 , respectively. As is shown in Fig. $7 \mathrm{~d}$, the mean temperature error ratio $\overline{\eta_{(\mathrm{AB})}}$, the standard deviation of $\eta_{(\mathrm{AB})}$, the total number of sampling $n$, the upper $95 \%$ confidence interval, and the lower $95 \%$ confidence interval are 1.5, 0.035, 110, 1.57, and 1.43 , respectively. The mean temperature error ratio $\overline{\eta_{(\mathrm{AC})}}$, the standard deviation of $\eta_{(\mathrm{AC})}$, the total number of sampling $n$, the upper $95 \%$ confidence interval, and the lower $95 \%$ confidence interval are 1.21 , $0.029,110,1.27$, and 1.15 , respectively. The mean temperature error ratio $\overline{\eta_{(\mathrm{BC})}}$, the standard deviation of $\eta_{(\mathrm{BC})}$, the total number of sampling $n$, the upper $95 \%$ confidence interval, and the lower $95 \%$ confidence interval are $0.81,0.028,110,0.86$, and 0.76 , respectively.

To further verify the accuracy of the spherical temperature sensor array, another two days of field observed data are adopted. A number of comparisons between the reference temperature results and the calculated temperature results provided by the sensor array have been performed. The calculated temperature results $\left[T_{(\mathrm{AB})}\right.$, $T_{(\mathrm{AC})}$, and $\left.T_{(\mathrm{BC})}\right]$ can be obtained by substituting the measured results $\left(T_{\mathrm{A}}, T_{\mathrm{B}}\right.$, and $\left.T_{\mathrm{C}}\right)$ and the mean temperature error ratios $\left[\overline{\eta_{(\mathrm{AB})}}=1.5, \overline{\eta_{(\mathrm{AC})}}=1.21, \overline{\eta_{(\mathrm{BC})}}=0.81\right]$ into Eq. (7). The mean calculated temperature results $T_{(\mathrm{ABC})}$ are provided by $T_{(\mathrm{AB})}, T_{(\mathrm{AC})}$, and $T_{(\mathrm{BC})}$. The reference temperature results $T_{\text {ref }}$ are provided by the temperature sensor inside the $076 \mathrm{~B}$ aspirated radiation shield. The differences between $T_{(\mathrm{AB})}$ and $T_{\text {ref }}, T_{(\mathrm{AC})}$ and $T_{\text {ref }}, T_{(\mathrm{BC})}$ and $T_{\text {ref }}$, and $T_{(\mathrm{ABC})}$ and $T_{\text {ref }}$ are shown in Fig. 8.

The results show that the mean difference between the calculated temperature results $T_{(\mathrm{AB})}$ and the reference temperature results $T_{\text {ref }}$ is $0.16 \mathrm{~K}$. The mean differences between $T_{(\mathrm{AC})}$ and $T_{\text {ref }}, T_{(\mathrm{BC})}$ and $T_{\text {ref }}$, and $T_{(\mathrm{ABC})}$ and $T_{\text {ref }}$ are $0.15,0.11$, and $0.14 \mathrm{~K}$, respectively. To further evaluate the accuracy of the spherical temperature sensor array, a root-meansquare error (RMSE) and a mean absolute error (MAE) are used: 


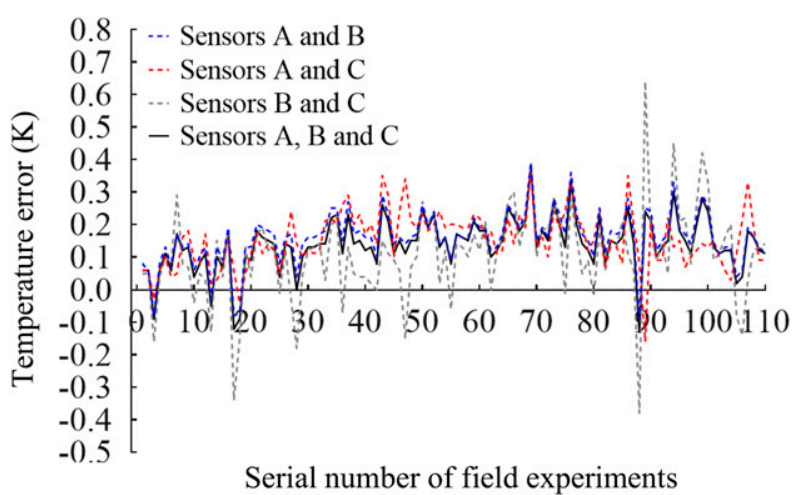

FIG. 8. Comparison among the temperature error results of the spherical temperature sensors $\mathrm{A}$ and $\mathrm{B}\left[T_{(\mathrm{AB})}-T_{\text {ref }}\right]$, sensors $\mathrm{A}$ and $\mathrm{C}\left[T_{(\mathrm{AC})}-T_{\mathrm{ref}}\right]$, sensors $\mathrm{B}$ and $\mathrm{C}\left[T_{(\mathrm{BC})}-T_{\mathrm{ref}}\right]$, and sensors $\mathrm{A}$, $\mathrm{B}$, and $\mathrm{C}\left[T_{(\mathrm{ABC})}-T_{\mathrm{ref}}\right] . T_{(\mathrm{AB})}, T_{(\mathrm{AC})}$, and $T_{(\mathrm{BC})}$ can be obtained by using Eq. (7). $T_{(\mathrm{ABC})}$ is the mean of $\left[T_{(\mathrm{AB})}, T_{(\mathrm{AC})}\right.$, and $\left.T_{(\mathrm{BC})}\right]$. $T_{\text {ref }}$ is provided by the reference sensor equipped with a $076 \mathrm{~B}$ aspirated radiation shield.

$$
\begin{aligned}
\text { RMSE } & =\sqrt{\frac{\sum_{i=1}^{n}\left(T_{\mathrm{cal}}-T_{\mathrm{ref}}\right)^{2}}{n},} \\
\mathrm{MAE} & =\frac{\sum_{i=1}^{n}\left|T_{\mathrm{cal}}-T_{\mathrm{ref}}\right|}{n},
\end{aligned}
$$

where $T_{\text {cal }}, T_{\text {ref }}$, and $n$ are the calculated air temperature provided by the spherical temperature sensor array, the reference air temperature, and the total number of sampling, respectively.

The RMSE and the MAE between the reference air temperature and the calculated air temperature given by the spherical temperature sensor array are 0.173 and $0.153 \mathrm{~K}$, respectively. The temperature error of the spherical temperature sensor array is an order of magnitude lower than that of traditional instruments. Hence, this new sensor array may provide a possibility of significant improvement of the air temperature observation accuracy to the order of $0.2 \mathrm{~K}$.

\section{Conclusions and future work}

In this paper, a spherical temperature sensor array is proposed. First, a series of analytical calculations based on the CFD method are performed to verify the design principle. Then, several simulations and observation experiments are conducted to verify the accuracy of this sensor array. The main conclusions and future works are as follows:

1) The simulation results show that the average difference between the temperature provided by the sensor array and the reference air temperature is $0.072 \mathrm{~K}$. The RMSE and the MAE between the temperature results provided this sensor array and the reference temperature results are 0.173 and $0.153 \mathrm{~K}$, respectively. These results indicated that the spherical temperature sensor array is expected to achieve an observation accuracy of $0.2 \mathrm{~K}$ based on well cleaning and maintenance.

2) This sensor array needs to be cleaned and maintained regularly to minimize the effect of weathering on the albedos. When the effect of weathering on the albedos reaches to a certain extent, there are three methods to overcome this effect. The first method is to replace the old sensor with a new one. The second method is to replace the old coating with a new coating. The third method is to replace the old temperature error ratio in Eq. (7) with a new ratio. In addition, to further improve the accuracy, we will continue to study the effect of weathering on the albedos in the future.

3) During daytime, due to solar radiation effect, the observed temperature is greater than the actual free air temperature. Because the temperature error induced by the longwave radiation during nighttime is much smaller than the temperature error caused by the solar radiation during daytime, we start this research by focusing on the relatively large temperature error during daytime. The study of the temperature error induced by the longwave radiation in the night is another complicated issue, which needs a lot of research in the future.

4) There are many other factors that may lead to a measurement uncertainty. It is difficult to analyze all the factors during the design process. To further improve the observation accuracy of this sensor array, we will continue to study the secondary factors in our model to make the model more consistent with the actual physical situation in the future. One of our main research directions is to quantify the temperature error ratio $\eta$ accurately. It may be necessary to transform this simple constant $(\eta)$ into a more complex matrix or a neural network algorithm by a method of artificial intelligence. If a high-accuracy $\eta$ is obtained, the accuracy of the sensor array may be further improved.

Acknowledgments. We would like to express appreciation for the valuable discussions with $\mathrm{Li}$ Zhang at TaiZhou Meteorological Observation Center. This work was funded by the University Natural Science Research Foundation of Jiangsu Province (Grant 18KJB530011), the Special Scientific Research Fund of Meteorological Public 
Welfare Profession of China (Grant GYHY200906037), the National Natural Science Foundation of China (Grants 41875035, 41605120), and the Priority Academic Program Development of Jiangsu Higher Education Institutions (Grant PAPD-III).

\section{REFERENCES}

Anderson, S. P., and M. F. Baumgartner, 1998: Radiative heating errors in naturally ventilated air temperature measurements made from buoys. J. Atmos. Oceanic Technol., 15, 157-173, https://doi.org/10.1175/1520-0426(1998)015<0157:RHEINV> 2.0.CO;2.

Baghapour, B., and P. E. Sullivan, 2017: A CFD study of the influence of turbulence on undercatch of precipitation gauges. Atmos. Res., 197, 265-276, https://doi.org/10.1016/j.atmosres.2017.07.008.

Davis, C. A., 2015: The formation of moist vortices and tropical cyclones in idealized simulations. J. Atmos. Sci., 72, 34993516, https://doi.org/10.1175/JAS-D-15-0027.1.

de Jong, S. A. P., J. D. Slingerland, and N. C. Van de Giesen, 2015: Fiber optic distributed temperature sensing for the determination of air temperature. Atmos. Meas. Tech., 8, 335-339, https://doi.org/10.5194/amt-8-335-2015.

Dillon, M. E., W. George, and R. B. Huey, 2010: Global metabolic impacts of recent climate warming. Nature, 467, 704-706, https://doi.org/10.1038/nature09407.

Erell, E., V. Leal, and E. Maldonado, 2005: Measurement of air temperature in the presence of a large radiant flux: An assessment of, passively ventilated thermometer screens. Bound.-Layer Meteor., 114, 205-231, https://doi.org/10.1007/ s10546-004-8946-8.

Fyfe, J. C., N. P. Gillett, and F. W. Zwiers, 2013: Overestimated global warming over the past 20 years. Nat. Climate Change, $\mathbf{3}$, 767-769, https://doi.org/10.1038/nclimate1972.

Georges, C., and G. Kaser, 2002: Ventilated and unventilated air temperature measurements for glacier-climate studies on a tropical high mountain site. J. Geophys. Res., 107, 4475, https:// doi.org/10.1029/2002JD002503.

Gleisner, H., P. Thejll, B. Christiansen, and J. K. Nielsen, 2015: Recent global warming hiatus dominated by low-latitude temperature trends in surface and troposphere data. Geophys. Res. Lett., 42, 510-517, https://doi.org/10.1002/2014GL062596.

Harrison, R. G., 2011: Lag-time effects on a naturally ventilated large thermometer screen. Quart. J. Roy. Meteor. Soc., 137, 402-408, https://doi.org/10.1002/qj.745.

— measurements in thermometer screens. Quart. J. Roy. Meteor. Soc., 138, 1114-1120, https://doi.org/10.1002/qj.985.

Holden, Z. A., A. E. Klene, R. F. Keefe, and G. G. Moisen, 2013: Design and evaluation of an inexpensive radiation shield for monitoring surface air temperatures. Agric. For. Meteor., 180, 281-286, https://doi.org/10.1016/j.agrformet.2013.06.011.

Huang, Y., M. M. Coggon, R. Zhao, H. Lignell, M. U. Bauer, R. C. Flagan, and J. H. Seinfeld, 2017: The Caltech Photooxidation Flow Tube reactor: Design, fluid dynamics and characterization.
Atmos. Meas. Tech., 10, 839-867, https://doi.org/10.5194/amt10-839-2017.

Hubbard, K. G., X. Lin, and E. A. Walter-Shea, 2001: The effectiveness of the ASOS, MMTS, Gill, and CRS air temperature radiation shields. J. Atmos. Oceanic Technol., 18, 851-864, https://doi.org/10.1175/1520-0426(2001)018<0851:TEOTAM $>$ 2.0.CO;2.

Hubbart, J. A., 2011: An inexpensive alternative solar radiation shield for ambient air temperature micro-sensors. J. Nat. Environ. Sci, 2, 9-14.

Kumar, P., S. K. Singh, P. Ngae, A. A. Feiz, and G. Turbelin, 2017: Assessment of a CFD model for short-range plume dispersion: Applications to the Fusion Field Trial 2007 (FFT-07) diffusion experiment. Atmos. Res., 197, 84-93, https://doi.org/10.1016/ j.atmosres.2017.06.025.

Lin, X., K. G. Hubbard, and G. E. Meyer, 2001a: Airflow characteristics of commonly used temperature radiation shields. J. Atmos. Oceanic Technol., 18, 329-339, https://doi.org/ 10.1175/1520-0426(2001)018<0329:ACOCUT>2.0.CO;2.

,,-- and E. A. Walter-Shea, 2001b: Radiation loading model for evaluating air temperature errors with a non-aspirated radiation shield. Trans. ASAE, 44, 1299-1306, https://doi.org/ 10.13031/2013.6435.

,,-- and C. B. Baker, 2005: Surface air temperature records biased by snow-covered surface. Int. J. Climatol., 25, 1223 1236, https://doi.org/10.1002/joc.1184.

Lopardo, G., F. Bertiglia, S. Curci, G. Roggero, and A. Merlone, 2014: Comparative analysis of the influence of solar radiation screen ageing on temperature measurements by means of weather stations. Int. J. Climatol., 34, 1297-1310, https:// doi.org/10.1002/joc.3765.

Mahajan, R. L., B. M. Fichera, and T. W. Horst, 2005: Mechanically aspirated radiation shields: A CFD and neural network design analysis. Int. J. Heat Mass Transfer, 48, 2856-2867, https:// doi.org/10.1016/j.ijheatmasstransfer.2005.01.026.

Qian, Y., Z. Han, J. Zhan, X. Liu, and G. Xu, 2018: Comparative evaluation of heat conduction and radiation models for CFD simulation of heat transfer in packed beds. Int. J. Heat Mass Transfer, 127, 573-584, https:// doi.org/10.1016/j.ijheatmasstransfer.2018.06.127.

Stafford, J., R. Grimes, and D. Newport, 2012: Development of compact thermal-fluid models at the electronic equipment level. J. Therm. Sci. Eng. Appl., 4, 031007, https://doi.org/ 10.1115/1.4006715.

Thomas, C. K., and A. R. Smoot, 2013: An effective, economic, aspirated radiation shield for air temperature observations and its spatial gradients. J. Atmos. Oceanic Technol., 30, 526537, https://doi.org/10.1175/JTECH-D-12-00044.1.

van der Meulen, J. P., and T. Brandsma, 2008: Thermometer screen intercomparison in De Bilt (The Netherlands), Part I: Understanding the weather-dependent temperature differences). Int. J. Climatol., 28, 371-387, https://doi.org/10.1002/joc.1531.

Xiong, X., X. Ye, and Y. Zhang, 2017: A quality control method for surface hourly temperature observations via gene-expression programming. Int. J. Climatol., 37, 4364-4376, https://doi.org/ 10.1002/joc.5092. 